\title{
CONCEPT OF RISK AND VISUALIZATION OF ITS CHANGES IN THE REPORTS OF THE INTERGOVERNMENTAL PANEL ON CLIMATE CHANGE
}

\author{
G.E. Insarov ${ }^{1)}$, C.L. Méndez ${ }^{2)}$, S.M. Semenov ${ }^{1,3,4)}$, P.Z. Yanda ${ }^{5)}$ \\ 1) Institute of Geography of the Russian Academy of Sciences, \\ 29 Staromonetny Lane, 109017, Moscow, Russian Federation; \\ * corresponding author: insarovg@gmail.com \\ ${ }^{2}$ Venezuelan Institute for Scientific Research, \\ 21827, Caracas 1020-A, Venezuela; carlos.menvall@gmail.com \\ ${ }^{3)} \mathrm{Yu}$. A. Izrael Institute of Global Climate and Ecology,
}

20B Glebovskaya str., 107258, Moscow, Russian Federation; SergeySemenov1@yandex.ru

${ }^{4)}$ National Research University 'Higher School of Economics', 20 Myasnitskaya str., 101000, Moscow, Russian Federation

5) University of Dar es Salaam,

P.O. BOX 33453, Dar es Salaam. Tanzania; pyanda@gmail.com

\begin{abstract}
Decision making in the field of limiting anthropogenic impacts on the climate system, including climate itself, requires the estimates of consequences. The assessment of the confidence of estimates is important for the reliable justification of the decisions, in particular, for the risk analysis. Such an approach was developed in the scientific reports of the Intergovernmental Panel on Climate Change (IPCC), in contributions of its Working Group II 'Impacts, adaptation and vulnerability'. The paper presents the evolution of the risk concept in the IPCC scientific reports and current understanding of risk in the latest special reports of 2018-2019. This understanding is based on the fact that risk arises from the interaction of three factors: the presence of a climate related hazard, the exposure of an affected object to the hazard and object vulnerability. The construction of 'burning ember diagrams', BE-diagrams, is used in the IPCC reports as the main approach for the aggregation and visualization of information on climate related changes in risk levels for natural and socio-economic systems, as well as for human health. However, the BE-diagrams presented in publications demonstrate some imperfections, and the procedure for constructing BE-diagrams in the IPCC reports is not sufficiently formalized. BE-diagrams are based on analyzing and summarizing data and information of two kinds: (a) field observations' results, experimental and modelling data available from the scientific literature; (b) IPCC expert judgements. However, the IPCC published no clear procedure that would include the sequence of steps, starting from (a) and (b), required to assess risks and to build corresponding BE-diagrams. The paper
\end{abstract}


provides an example of such a procedure, i.e. an algorithm for the construction of a visual image summarizing the assessment of adverse effects of climate warming on an agricultural crop, specifically, spring wheat. The demonstrated approach to the construction of BE-diagrams can be generalized and used in the development of BE-diagrams for the other elements of natural or socio-economic systems affected by climate change. To ensure the transparency of assessments of climate change impacts performed with BE-diagrams and to allow users to repeat the assessments, a special IPCC Guidance note on this issue is needed.

Keywords. Climate change, impact, risk, assessment, visualization, methodology, Intergovernmental Panel on Climate Change, special reports, assessment reports.

\section{Introduction}

The concept of risk is crucial for assessing the effects of climate change on natural and socio-economic systems and on human health. In the IPCC reports risk is determined for specific impacts associated with climate change (see, e.g., (IPCC, 1990; IPCC, 2014)). This can be a manifestation of a hydrometeorological hazard (for example, flooding), or any other hydrometeorological factor in general (for example, an anomaly of air temperature in the surface layer). Furthermore, risk is determined for a particular object or for a group of objects experiencing this impact.

Risk can be quantified. Consider the set of events $A_{0}, A_{1}, A_{2}, \ldots, A_{N}$, which correspond to the increasing intensity of a hydrometeorological hazard or other factor. For example, these events can be floods ordered by increasing maximum water level, or heat waves ordered by the magnitude of temperature anomaly. We assume that $\mathrm{A}_{0}$ means no impact (zero intensity). We denote the probabilities of the occurrence of these events in a certain period of time (say, the summer season) by $P_{0}, P_{1}, P_{2}, \ldots, P_{\mathrm{N}}$. Let us assume that in this period of time only one of these events can occur, and one necessarily occurs, i.e. the sum of these probabilities is 1 . If damage values arising due to respective events $A_{0}, A_{1}, A_{2}, \ldots, A_{N}$ are denoted by $D_{0}, D_{1}, D_{2}, \ldots, D_{\mathrm{N}}\left(D_{0}=0\right.$, there is no damage), then the risk value $R$ is calculated as follows:

$$
R=P_{0} D_{0}+P_{1} D_{1}+P_{2} D_{2}+\ldots+P_{\mathrm{N}} D_{\mathrm{N}}
$$

Such quantitative expression of risk corresponds, for example, to understanding of risk given in (Laplace, 1902; Morgan, Henrion, 1990; Rosa, 1998). Von Neumann-Morgenstern utility (vNM expected utility function) can also be described by (1), where $D_{i}$ are possible outcomes of a lottery (von Neumann, Morgenstern, 1970). It should be noted that neither the first terms of the sum corresponding to events of low intensity nor the last ones corresponding to events of high intensity might be the main contributors to the sum. The intermediate terms of the sum may contribute the most to the formation of risk $R$, see Fig.1. Figure 1 shows the characteristics of possible manifestation of a hazard, namely water level 
rise in a river during a rain flood by $1,2, \ldots, 7 \mathrm{~m}$, the probabilities of these events, and the corresponding damage values in conventional units.

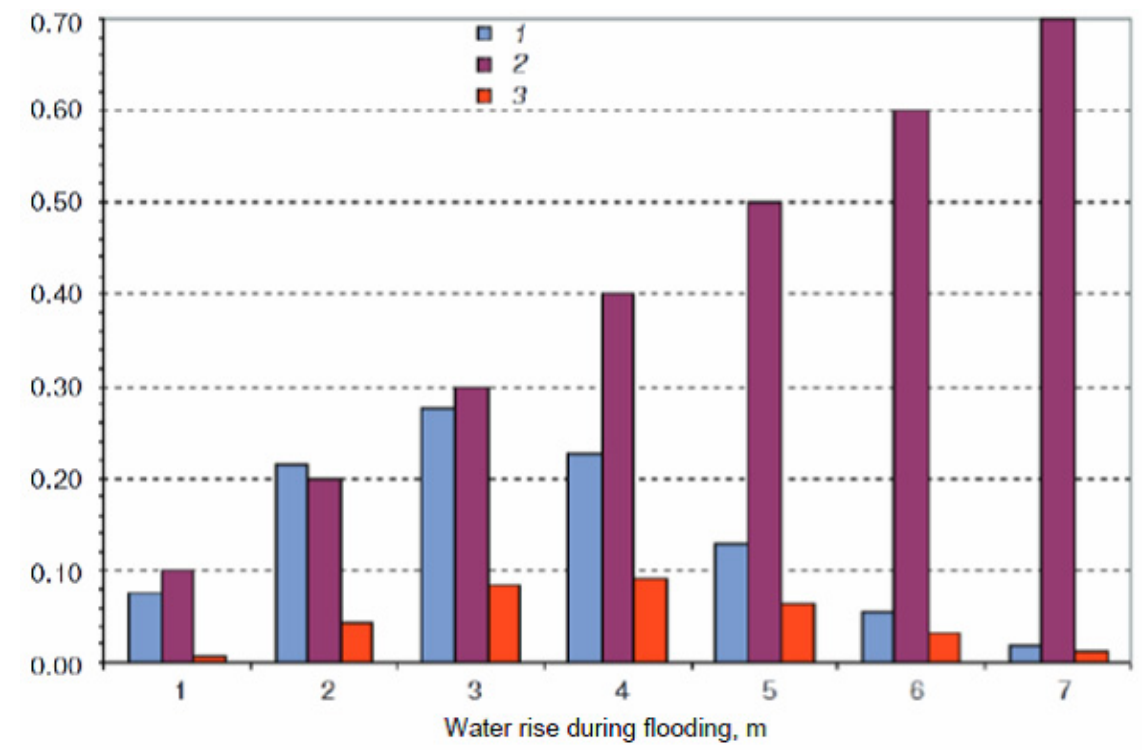

Figure 1. Illustration of the concepts of probability of a hazardous event, damage, and risk

(Fig. 1.3 from (Semenov et al., 2008), as amended)

1 - the probability of rising water in the river during a rain flood by $1-7 \mathrm{~m} ; 2$ - damage in conventional units; 3 - corresponding values of risk components, i.e. the terms in formula (1)

An important aim of all international efforts on limiting anthropogenic impact on the Earth's climate system is to reduce the risks associated with anthropogenic changes in the global climate (UNFCCC, 1992; Kyoto Protocol, 1997; Paris Agreement, 2015). This can be achieved either by reducing anthropogenic impact on the climate system (mitigation), which may decrease the intensity of climatedriven events, or by adaptation to growing climate changes, which reduces their consequences. Mixed strategies can also be applied.

The IPCC provides the international climate negotiation process with diverse scientific information needed to come up with solutions to global climate policy, including information on the risks associated with changes in the global climate. The IPCC extracts this information from the world scientific literature, which is very extensive and heterogeneous. In addition, given the complexity and high uncertainty of some human and natural processes involved, which are currently difficult or even impossible to quantify, a substantial part of the assessment is accomplished by the IPCC expert judgments (EJ) based on the scientific literature. One of the most notable IPCC visualization tools for the presentation of aggregated data on climate related risks is burning ember diagrams, BE-diagrams. Very often, BE-diagrams are constructed with the involvement of EJ outcomes. Although some attempts to formalize the EJ methodology has been undertaken using various approaches (see, e.g., (Morgan, Henrion, 1990; Aspinall, Cooke, 2013; Mach et al., 2017)), the objective result of EJ cannot be guaranteed, i.e., a bias is possible. Therefore, the development of the IPCC procedure for EJ is extremely important 
for assuring transparency, reproducibility, and consistency in the assessment outcomes.

In order to contribute to the transparency and reproducibility of the IPCC assessment processes, the objectives of this paper are:

- to present the evolution of the concept of risk in the IPCC reports and current insights into its interpretation;

- to describe BE-diagrams as a means of summarizing and visualizing information about climate related risks;

- to indicate the need for substantial refinement of the methodology for construction of BE-diagrams;

- to exemplify the formalization of the construction procedure.

\section{The evolution of the concept of risk in the IPCC reports and its current understanding}

The term 'risk' has been used in all IPCC assessment reports (AR), starting with the first one (FAR) published 30 years ago (IPCC, 1990). According to one of the chapters of AR4, risk is a combination of magnitude of the impact on an object and the probability of its occurrence. Furthermore, in assessing risk, one should take into account the uncertainty of the climate change process, the object's exposure to the impact (see below), its sensitivity and adaptation capacity (Schneider et al., 2007, p. 781).

During the second, third, and fourth assessment cycles the risk concept was often applied in the IPCC reports. The IPCC special report Managing the Risks of Extreme Events and Disasters to Advance Climate Change Adaptation (SREX) contributed much to the development of the risk concept and its explicit application in risk assessment, although it was limited to the issues of climate related disaster management, see chapter 1 of (IPCC, 2012).

In the Fifth Assessment Report cycle, the development of the concept of risk was intensive and its application became explicit. A general risk concept was formulated and included into the glossary accompanying the report (IPCC, 2014). The concept has been refined on the basis of E.A. Rosa studies (Rosa, 1998; 2003). In these publications, risk is defined as a potential result of a game with an uncertain outcome, in which something of value is at stake (the notion of value is interpreted broadly). Often risk is understood as a product of probability of a hazard by intensity of the impact that the hazard triggers if it occurs. The risk arises as a result of the interaction of the hazard, exposure of the object to the hazard and the object vulnerability.

Note that the risk concepts used in all the IPCC reports are based on risk definitions that are widely discussed in the scientific literature (see, for example, (Aven, Renn, 2015)). Similar definitions are also applied in the thematic reports of some other international organizations, see, e.g., (The Global Risks Report, 2019; IPBES, 2019). In relation to climate change, in the IPCC ARs the concept of risk is used as a characteristic of negative future impacts on socio-economic and ecological systems. 
The current understanding of climate related risk was developed in the IPCC Fifth Assessment Report cycle and was used in the last three IPCC special reports (IPCC, 2018; IPCC, 2019a; IPCC, 2019b). The IPCC Working Group II "Impacts, Adaptation and Vulnerability" (IPCC, 2014) made the major contribution to the development of this concept. The modern concept does not contradict the classical understanding set forth in the Introduction: risk is expected damage to a specific object with regard to the likelihood of a climate related event and the impact that emerges when this event occurs. However, when finalizing the concept, much attention was paid to the process of risk formation, to the factors on which the risk depends.

So, for a pair 'a climate-driven event - an affected object' three factors are considered:

- the intensity of the event manifestation, namely, of a climate related hazard or other climate related factor;

- exposure of the object to this hazard or factor;

- vulnerability of the object to this hazard or factor.

Let us explain these categories.

Hazard is a hydrometeorological anomaly or trend, for example, an extreme rainfall or a long period of dry and hot weather, i.e. heat wave. These events can be characterized quantitatively, for example, by the duration of the anomaly and its magnitude (precipitation sum, temperature value). Event intensity is determined with the combination of anomaly duration and magnitude. In the simplest case, an event is characterized by probability and intensity. In the case of trend, its rate is taken into account. In the analysis, it is sometimes convenient to distinguish between primary hazards (for example, an extreme rainfall, a heat wave) and secondary (consequent) ones (floods, forest/peat fires, respectively), which pose threats to the life, health and livelihood of people.

Exposure is an attribute of the object of climate related impact. It quantifies the probability of contact with a hazard or other influencing factor, provided that the event has occurred. If the event is a flood of certain intensity and the object is the housing stock of a settlement, then exposure can be characterized by the percentage of houses in the flood zone. If the event is a heat wave and the object is population of an area, then exposure can be characterized by the percentage of residents who are forced to work and/or live outside air-conditioned premises due to their profession or financial condition.

Vulnerability is also an attribute of the object of influence. It determines the severity of event consequences provided that the object and the event had a contact. This property characterizes the ability of the object to withstand hazard. For a building that has got into a flood zone during flooding, this ability means its strength, which determines the probability of withstanding the torrent (the lower the strength is, the higher the vulnerability is). For a person who has been exposed to a heat wave, this includes the general state of his health, the possibility of obtaining urgent medical care, etc.

Reduction of probability and intensity of the event as well as the exposure and vulnerability of the object reduce the risk. People can influence primary negative 
climate related events towards reducing their probability and intensity only through mitigation, i.e. limiting anthropogenic impact on the climate system. Exposure and vulnerability can be reduced by adapting objects affected by a changing climate. Adaptation is carried out during the implementation of a system of measures aimed specifically at reducing exposure and vulnerability.

With climate change, additional risks can arise both from an increase in the intensity of climate related events and from an increase in exposure and/or vulnerability. The latter can also occur as a result of adaptation to other factors. For example, walks in some forested areas, on one hand, contribute to strengthening the general state of human health, and on the other, in the warm season, increase the likelihood of contact with ticks, vectors of dangerous human diseases.

\section{BE-diagrams: a tool for synthesizing and visualizing the results of climate change impact assessments}

\section{Use of BE-diagrams in the IPCC reports: retrospective}

In the IPCC reports, BE-diagrams first appeared in one of the chapters of the Third Assessment Report (TAR) in the contribution of Working Group II "Impacts, Adaptation and Vulnerability" (WG II). It was a black and white drawing, in which gradually thickening shades of gray corresponded to the growth of some risks associated with increasing temperature (Fig. 2). Each risk was represented by a separate bar. The drawing was illustrative, as can be seen from its caption.

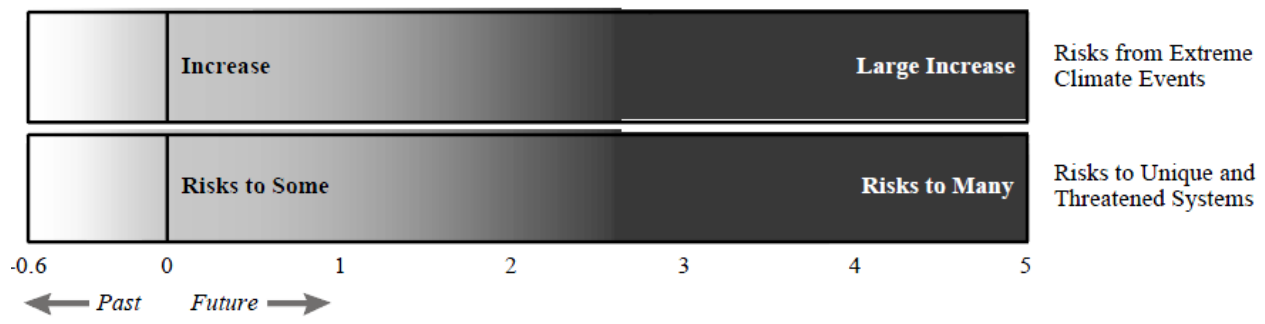

Increase in Global Mean Temperature after $1990\left({ }^{\circ} \mathrm{C}\right)$

Figure 2. Risks from climate change, by reasons for concern: risks from extreme climatic events (the upper part) and for unique and threatened systems (the lower part) (the fragment of Fig. 19-7

from (Smith et al., 2001))

'Shades correspond to severity of impact or risk. White means no or virtually neutral impact or risk, light gray means somewhat negative impacts or low risks, and dark gray means more negative impacts or higher risks. Global average temperatures in the 20th century increased by $0.6^{\circ} \mathrm{C}$ and led to some impacts. Impacts are plotted against increases in global mean temperature after 1990.

This figure addresses only how impacts or risks change as thresholds of increase in global mean temperature are crossed, not how impacts or risks change at different rates of change in climate. Temperatures should be taken as approximate indications of impacts, not as absolute thresholds'

(Smith et al., 2001)

The same drawing, but in colors, appeared in the Technical Summary of the WGII contribution to TAR (Fig. 3, the left panel). The bars were replaced with columns. The absence of risk was shown with the white color. The light gray color corresponding to a small risk was replaced with yellow, and the dark gray denoting a more significant risk was replaced with red. Transition of colors was made 
gradual. A similar color drawing was included in the Summary for Policymakers of the WGII contribution to TAR. It was added to the caption that the average annual global temperature is used to characterize climate change, and future risks are a function of not only climate change but also of socio-economic conditions and adaptation. Thus, the illustrative nature of the drawing was emphasized.

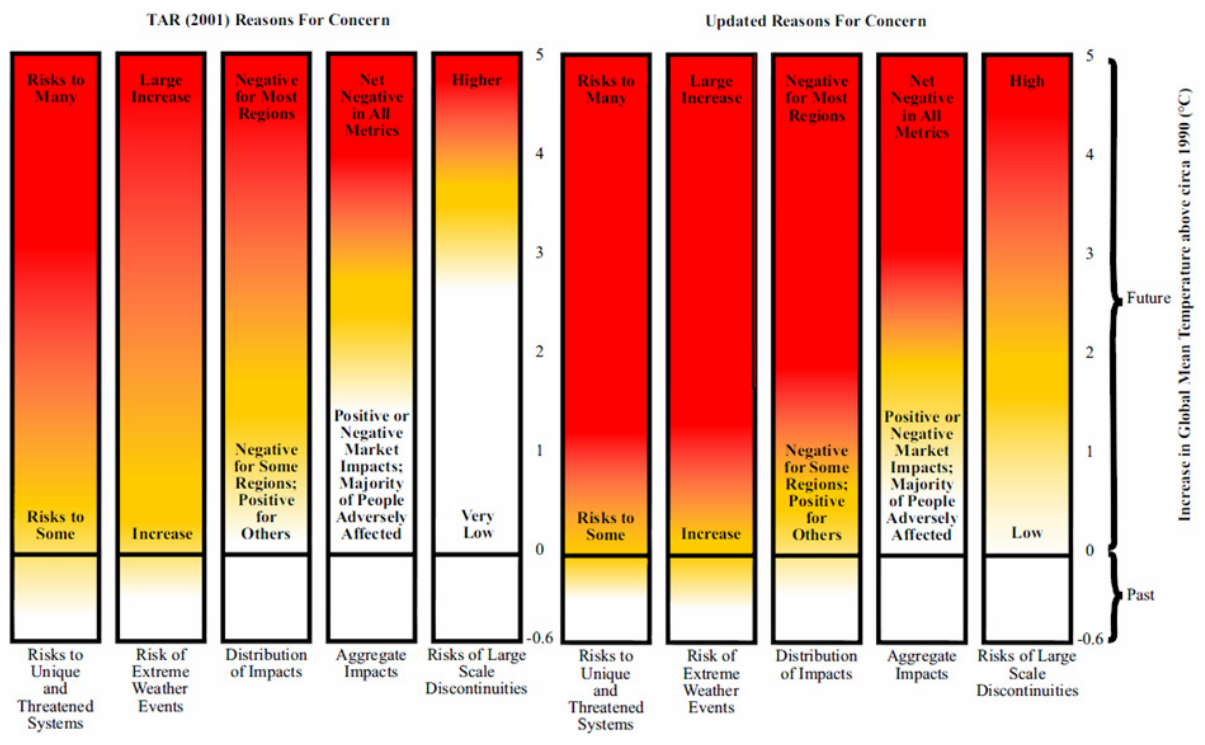

Figure 3. Risks caused by climate change. On the left: the BE-diagram from TAR; on the right: a diagram based on updated information (Fig. 1 from (Smith et al., 2009))

The authors of the Fourth Assessment Report (AR4) refrained from using the columnar BE-diagrams in the Summary for Policymakers, although they included figure TS.6 in the Technical Summary (Parry et al., 2007) which lists the risks associated with climate change for ecosystems. The background was a smooth transition from one to another in white, yellow, and red colors, which have the same meaning as in the columnar charts of the TAR.

Shortly after the release of AR4, a group of its authors published an article (Smith et al., 2009) which shows the BE-diagram from TAR and a similar new BE-diagram plotted using the information published after the release of TAR, see Fig. 3. As seen from the right panel, there are more reasons for concern for all types of risks, for each column a larger area is red. It was concluded that a slight increase in average global air temperature since the release of TAR, i.e. less than over the decade, led to such significant consequences and increased the reasons for concern. Paper (Fischlin, 2009) also compares the TAR BE-diagrams with those in (Smith et al., 2009).

In AR5, BE-diagrams reappear. The diagram in chapter 19 is similar to the right diagram in Fig. 3, but there are some differences. The fourth color is introduced, purple (violet), denoting a very high risk. In addition, it is indicated that the risk levels shown reflect the judgments of this chapter authors. This figure is also included in the Technical Summary, in the Summary for Policymakers of AR5 (IPCC, 2014) and in the Synthesis Report (IPCC, 2014a). The latter report includes 
another figure containing BE-diagrams illustrating the risk for terrestrial and freshwater species associated with global warming, the risk for marine organisms related to ocean acidification or the combined effect of ocean acidification and warming, and the risk associated with sea level rise for coastal systems.

Shortly after the release of AR5, a group of its authors published an article (Gattuso et al., 2015) in which BE-diagrams were constructed to illustrate the observed changes and future risks for marine organisms and ecosystem services under the influence of warming and ocean acidification. A similar diagram (see Fig. 4) is presented in the IPCC Special Report on the Ocean and Cryosphere in a Changing Climate (IPCC, 2019b). BE-diagrams from the Summary for Policymakers and the Synthesis Report of AR5 are also analyzed in (O'Neill et al., 2017).

Three special reports ${ }^{1)}$ have already been published in the IPCC sixth assessment cycle: Global warming of $1.5^{\circ} \mathrm{C}$ (IPCC, 2018), Climate change and land (IPCC, 2019a), Special report on the ocean and cryosphere in a changing climate (IPCC, 2019b). All of them contain BE-diagrams characterizing the corresponding risks, although no IPCC procedure for the construction of such diagrams has been published as a guidance note for IPCC authors.

\section{Issues in the practice of the use of BE-diagrams in the IPCC reports}

IPCC scientific reports started using BE-diagrams, especially in their Summary for Policymakers, due to the necessity to somehow aggregate and visualize data on various consequences for natural and socio-economic systems and for human health caused by increasing air temperature in the surface layer and, in general, by a directional change in any parameter of climate. As climate policy developers are hardly able to navigate through the wide variety of initial observations, experiments, and model calculations, it would be inefficient to provide them with the latter. Unfortunately, the existing BE-diagrams in the IPCC scientific reports are not accompanied by sufficient information on many significant technical details. To exemplify this, let us consider a BE-diagram from the most recent IPCC report (IPCC, 2019b) shown in Fig. 4.

The diagram describes the impacts and risks to coastal and oceanic ecosystems associated with climate change. The change in the average global temperature in the surface layer relative to the pre-industrial level is indicated in ${ }^{\circ} \mathrm{C}$ on the left vertical axis, and the average ocean surface temperature is indicated on the right vertical axis. The vertical columns represent additional warming impacts and risks for the following objects: warm-water corals, kelp forests, seagrass meadows, epipelagic ecosystems, rocky coast ecosystems, salt marshes, cold-water corals, estuary ecosystems, sandy coast ecosystems, mangroves, and abyssal plain ecosystems. Colors characterize additional impacts and risks arising when respective temperature thresholds are exceeded (IPCC, 2019b). Purple indicates very high probability of strong impacts/risks and significant irreversibility, persistent climate related threats, combined with a limited ability to adapt due to the

\footnotetext{
1) For the first two reports, their short titles are given.
} 
nature of the threat or impacts/risk. Red indicates significant and widespread impacts/risks, yellow is for the impacts/risks which are detectable and attributable to climate change with at least medium confidence, and white means that no impacts/risk is detectable. Transition ranges are vertical lines. Their confidence level is characterized qualitatively (Mastrandrea at al., 2010) as follows: low (•), medium $(\bullet \bullet)$, high $(\bullet \bullet \bullet)$, very high $(\bullet \bullet \bullet \bullet)$.

(d) Impacts and risks to ocean ecosystems from climate change

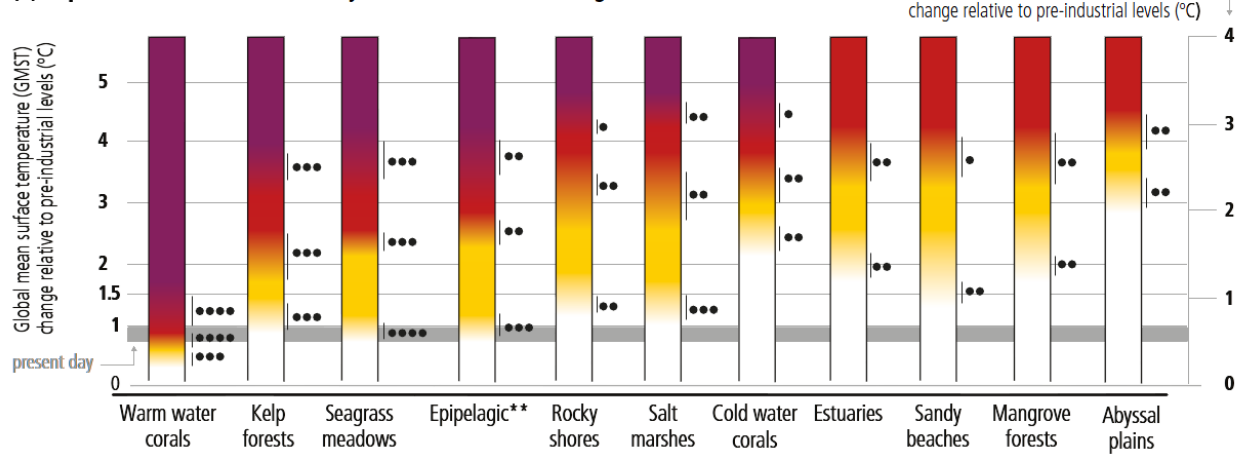

Figure 4. Assessment of risks for coastal and open ocean ecosystems based on observed and projected climate impacts on ecosystem structure, functioning and biodiversity (the fragment of Fig. SPM.3 from (IPCC, 2019b))

'Impacts and risks are shown in relation to changes in Global Mean Surface Temperature (GMST) relative to pre-industrial level. Since assessments of risks and impacts are based on global mean Sea

Surface Temperature (SST), the corresponding SST levels are shown ${ }^{2}$. The assessment of risk transitions is described in Chapter 5 Sections 5.2, 5.3, 5.2.5 and 5.3.7 and Supplementary Materials SM5.3, Table SM5.6, Table SM5.8 and other parts of the underlying report. The figure indicates assessed risks at approximate warming levels and increasing climate related hazards in the ocean: ocean warming, acidification, deoxygenation, increased density stratification, changes in carbon fluxes, sea level rise, and increased frequency and/or intensity of extreme events. The assessment considers the natural adaptive capacity of the ecosystems, their exposure and vulnerability. Impact and risk levels do not consider risk reduction strategies such as human interventions, or future changes in non-climatic drivers. Risks for ecosystems were assessed by considering biological, biogeochemical, geomorphological and physical aspects. Higher risks associated with compound effects of climate hazards include habitat and biodiversity loss, changes in species composition and distribution ranges, and impacts/risks on ecosystem structure and functioning, including changes in animal/plant biomass and density, productivity, carbon fluxes, and sediment transport. As part of the assessment, literature was compiled and data extracted into a summary table. A multi-round expert elicitation process was undertaken with independent evaluation of threshold judgement, and a final consensus discussion. Further information on methods and underlying literature can be found in Chapter 5, Sections 5.2 and 5.3 and Supplementary Material. \{3.2.3, 3.2.4, 5.2, 5.3, 5.2.5, 5.3.7, SM5.6, SM5.8, Figure 5.16, Cross Chapter Box 1 in Chapter 1 Table CCB1\}' (IPCC, 2019b)

In spite of the potential practical usefulness of this method of aggregating and visualizing information, there are several points that need additional attention and methodological refinement.

Firstly, in the color legend of Fig. 4 (see above) the description of gradations of risks denoted by colors is quite vague. It is difficult to use it for practical assessment of significance of consequences.

2) The conversion between GMST and SST is based on a scaling factor of 1.44 derived from changes in an ensemble of RCP 8.5 simulations; this scaling factor has an uncertainty of about $4 \%$ due to differences between the RCP2.6 and RCP8.5 scenarios. \{Table SPM.1.\} 
Secondly, special software is used to draw color transitions for this and similar diagrams. Such diagrams got their name, BE-diagrams, due to the similarity with smoldering coals. However, note that on the one hand, the applied software and adopted parameters determining the size of transition zones between colors in Fig. 4 are not indicated. On the other hand, locations of temperature thresholds and their ranges of uncertainty are not shown explicitly neither in Fig. 4, nor in the caption, while only they matter in the further practical use of such diagrams. Thus, smooth transitions between colors that indicate risk levels just add uncertainty to the assessment of information contained in scientific literature. In particular, this makes it difficult to repeat the assessment procedure and verify its results, because guiding principles of the development of the diagrams are not formalized. Hence, the assessment procedure (algorithm) for the identification of temperature thresholds mentioned in the Fig. 4 caption (but masked by gradual color filling) remains unclear. The phrase 'A multi-round expert elicitation process was adopted with independent evaluation of threshold judgement, and a final consensus discussion' presented in the caption to Fig. 4 does not add clarity to the point.

Thirdly, it is also unclear how the data on impacts and risks may be combined in one figure. In fact, for the latter it is necessary to have the estimates of the probability of temperature changes, which are not presented neither in the figure, nor in the caption.

Fourthly, the way of data aggregation remains unclear, in particular, how changes in the temperature values in locations and seasons discussed in the underlying publications were converted to the global mean temperature changes indicated on the vertical axes in Fig. 4.

These shortcomings are also inherent to the BE-diagrams presented in the earlier IPCC reports.

In accordance with the IPCC basic principles, 'The role of the IPCC is to assess on a comprehensive, objective, open and transparent basis the scientific, technical and socio-economic information relevant to understanding the scientific basis of risk of human-induced climate change, its potential impacts and options for adaptation and mitigation' (Principles Governing IPCC Work, 2013). Traceable account of the assessment procedure and possibility to repeat the assessment using the same initial data are the fundamental principles of the IPCC work, which are vitally important for obtaining high rating in the IPCC reports. It is on these grounds that methodological approaches used in developing the diagrams should be clearly articulated to ensure reliability of the information presented in the diagrams and possibility for replication of a similar process.

Requirements for the processing of scientific data were formulated more than 30 years ago and have been subsequently developed. They are currently known as FAIR Data Principles. That is, data should be Findable, Accessible, Interoperable, and Reusable (e.g. (Wilkinson et al., 2016)). The IPCC Task Group on Data Support for Climate Change Assessments (TG-Data) is developing Guidelines to support the IPCC authors and Technical Support Units in the following FAIR principles for the IPCC data and material (TG-Data, 2020). It is also proposed that the data which served as a base for drawings, tables, and all the main results 
included in the Summary for Policymakers and Technical Summary of contributions of all Working Groups, as well as in the Synthesis Report of the AR6, should be consistent with the principles and practice of FAIR. The authors are to present data along with description of the methods for data generalization used in the construction of the figures. The archiving and reliable storage of data should be carried out by the IPCC Data Distribution Center. It ensures the availability of data and algorithms by which the figures are obtained, and thereby guarantees the transparency of all procedures and possibility of their repetition by users in accordance with the IPCC principles (Stockhause et al., 2019).

Since the release of FAR, there has been a substantial increase in the number of scientific publications on climate change. During the IPCC Fifth Assessment Cycle, the number has increased approximately by factor 75 versus the number of the FAR cycle (Haunschild et al., 2016; Minx et al., 2017). The lower estimate of the number of publications indexed by the Web-of-Science during the AR5 was 110,000. Over 2016, more than 33,000 papers were published (except 'gray' literature, peer-reviewed publications not included in the Web-of-Science, and some others). Thus, the load on the IPCC authors has substantially increased.

The total number of references to original works in AR5 was approximately twenty times greater than in FAR (Minx et al., 2017). This increase, however, is by about three times smaller than increase in the total number of publications on climate change. A coverage of literature, i.e., the share of literature used, has decreased approximately by the same factor: it was $63 \%$ in FAR and only $23 \%$ in AR5. So, the question is which publications are used in assessment reports? Should all climate related publications be considered, or only a part of them? If only a part, what are the selection criteria? How to synthesize information from a large number of publications with heterogeneous information? Some approaches and recommendations can be found in (Lokers et al., 2016; Nunez-Mir et al., 2016). Here we would like just to mention that these issues are directly related to the assessment of risks arising from climate change and should be considered in the IPCC Guidance for the assessment of such risks and their visualization.

The need for a Guidance on transparent aggregation of data and information for the IPCC assessments has been emphasized in many scientific publications (e.g., see (Minx et al., 2017)) and references in this work). In order to adequately address the issues related to the sources of risks and uncertainties, it is necessary to develop various approaches and tools for the solution of the related problems. Currently, given the availability of a small set of tools only, the best available ones should be included in the IPCC Guidance. If the authors of future reports use such a guidance, the readers will get the full picture of the scientific literature at the time of the assessment (what data are available and what data are not) for all the sectors and levels of generalization, namely, global, regional, and others. The description of the process of data generalization should inform readers where the source data end, and where the quantitative estimates obtained by the IPCC authors or their expert judgments begin, on which data or literature sources these estimates and judgments are based, by what methods they are obtained, and what the accuracy of the resulting estimates is. So, the readers of the reports, including decision-makers and 
their advisers, will obtain a more adequate and clear picture of the ongoing and expected consequences of climate change and associated risks. Advisers, many of whom are scientists, are able to read and understand not only the resulting graphs and charts but also the 'boring' tables of source data as well as the procedures for summarizing them and obtaining the resulting products. As a result, decision making based on accounting for the uncertainties clearly described by the IPCC will be more informed and better justified.

One of the basic IPCC tools for summarizing data contained in the scientific literature studying climate change impacts on natural and socio-economic systems and associated risks is so far the construction of BE-diagrams. Up to date, the process of constructing such diagrams in the IPCC scientific report has not been completely transparent, and a number of related questions arise (some of them we have formulated above). If BE-diagrams are included in AR6, the algorithm of constructing them should be described step by step, as a path from the source data extracted from climate related scientific publications to the colored columns of BE-diagrams. This algorithm should be clearly described in a way that the construction can be repeated by other IPCC experts as well as the readers and users of AR6, including science advisers to policymakers. For this, initial data and the algorithm should be accessible in the Report or in Supplementary materials to the Report.

If the authors of the IPCC AR6 follow a procedure for constructing BEdiagrams similar to that used in the IPCC special reports for 2018-2019 (e.g. IPCC, $2019 b$ ), they will encounter the following problem. One of the steps (namely, the identification of risk transition thresholds from one level to another, see the caption to Fig. 4) is actually the work for a group of experts. The results of this work, generally speaking, cannot be repeated, since another group of experts, even working according to the same protocols, will not necessarily come to the same results as the first group. The perceived severity of risk can be different for different experts, authors, or stakeholders (O'Neill et al., 2017). The lack of clarity in the procedure for constructing BE-diagrams disagrees with the basic principles of the IPCC. This questions the expediency of use of such diagrams in the IPCC reports in their present form and urges changing the existing practice of their construction.

Thus, the procedure for constructing BE-diagrams as a means of aggregating and visualizing information on the impacts of climate change on natural and socioeconomic systems and on human health, needs to be substantially refined and formalized, and the outcome should be published as a Guidance Note for the IPCC authors. A possible way for formalization is exemplified in the next section.

\section{An example of the formalization of a procedure for BE-diagram construction}

Our example is illustrative in relation to specific numbers, but in other respects it directly refers to reality. It is well known (Baraev et al., 1978) that in the temperate latitudes of the Northern Hemisphere spring wheat is sensitive to the temperature of June, when the ear is formed and some other important processes of 
plant development take place ${ }^{3)}$. Significant positive anomalies in the average air temperature in June may lead to undesirable consequences. We present them in order of increasing temperature values: a decrease in production of the total plant biomass, a decrease in grain production (i.e., yield), and a decrease in survival against the drying. Assume that we have a set of scientific publications that provide quantitative data, e.g., for the beginning of the 21 st century, describing these effects for a region where spring wheat is a typical crop (for example, for the Volga region, Russia). For the various farms, these data characterize anomalies in the average June temperature (say, against the normal of 1961-1990) and the values of the three effects mentioned above (in percent of the average values for the same base period). Of course, the data in the form of initial graphs and tables are difficult for assimilation by non-professionals. For these data aggregation and visualization, one can use the following technique.

We adopt that the level ' $10 \%$ or more' makes a climate related decrease in total biomass production, grain production (yield), and survival against the drying undesirable or as a reason for concern. For spring wheat, these undesirable effects begin showing on average with increasing positive temperature anomalies. If the thresholds of average June temperature anomaly are exceeded, respective undesirable consequences appear. Threshold values can be either directly extracted from the available data or evaluated with data processing by statistical or model methods. This can be done, for example, as follows.

Let us consider data from scientific publications: $\left\{X_{n}\right\}$ are data on any of the three variables (total biomass production, grain production (yield), survival from the drying), and $\left\{\Delta_{n} t\right\}, n=1.2, \ldots, N$, are respective temperature anomalies.

We apply the exponential model $X(\Delta t)=A \exp (-b \Delta t+\xi)$. Here $A$ and $b$ are the model parameters, and $\xi$ characterizes residual variability. It is associated with environmental factors that are non-directionally changing from year to year, e.g., with cloudiness. Parameter $A$, which has the meaning of the effect value at a zero temperature anomaly, characterizes systematic changes in factors of different origin (for example, changes in agricultural technology) since the basic time period 1961-1990.

If one goes to the logarithmic scale of variable $X$ and applies the usual linear regression technique of $\ln X$ to $\Delta t$, the estimate $b^{*}$ of parameter $b$, the estimate of its variance $\mathrm{D}_{b^{*}}$ and of the error $\sigma=\left(\mathrm{D}_{b^{*}}\right)^{1 / 2}$ can be obtained. If there are several such publications for the region under consideration, then all the obtained estimates of parameter $b$ can be aggregated into the most precise one using the Gauss method, i.e. through summing up the estimates with weights that are inversely proportional to the variance.

For a certain confidence level $P$ (i.e., for the probability of error $\varepsilon=1-P$ ), one can find the lower and upper confidence limits for $b$. We denote them by $b_{\min }$ and $b_{\text {max }}$, respectively. When verbally characterizing the selected confidence levels, the

3) The situation in the tropical regions is analogous: the rainfall and temperature patterns are among the key determinants of crop production. 
IPCC recommendations can be used (Mastrandrea et al., 2010): as likely as not for $0.33 \leq \varepsilon<0.66$; likely for $0.10 \leq \varepsilon<0.33$; very likely for $0.01 \leq \varepsilon<0.10$; virtually certain for $0.00 \leq \varepsilon<0.01$.

To estimate respective $\Delta t$ values, one needs to use the relationship $b \Delta t=-\ln (0.9)$ which corresponds to a $10 \%$ climate related decrease in $X$. At $b$ values equal to $b^{*}$, $b_{\min }$ and $b_{\max }$, we obtain an estimate of the corresponding threshold value of anomaly $\Delta t$ of the average June temperature and its lower and upper confidence limits, respectively.

In the Fig. 5, the values of $2,2.5$ and $3.5^{\circ} \mathrm{C}$ are conventionally adopted as respective threshold values $\Delta t$ for the three effects under consideration for the spring wheat, namely, a decrease in the production of the total biomass of a plant, a decrease in its grain production (i.e., yield), and a decrease in survival against the drying. Confidence intervals are shown by vertical bars. Confidence is indicated by dots (see the figure caption). Of course, when choosing stronger requirements for the probability of error, the boundaries of these intervals expand.

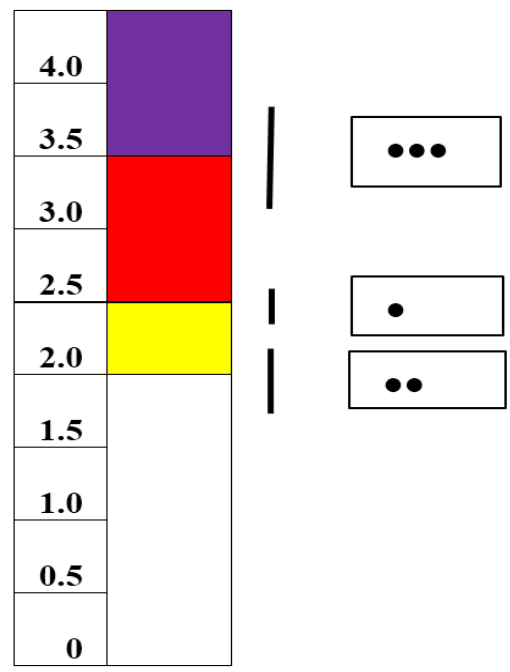

Figure 5. An illustrative example. The left column depicts the anomaly of mean temperature of June versus the 1961-1990 norm, ${ }^{\circ} \mathrm{C}$. The right column presents the temperature intervals in which new undesirable consequences for spring wheat crops occur

The emergence of new consequences is accompanied by a change in color from white to yellow for a decrease in the production of total plant biomass by $10 \%$ or more, from yellow to red for a decrease in grain production (i.e., yield) by $10 \%$ or more, from red to purple for a decrease in survival from the drying by $10 \%$ or more. The vertical bars on the right represent a range of uncertainty for respective threshold values, and dots indicate confidence levels for these ranges:

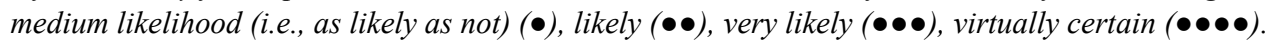
According to this scale, greater confidence corresponds to a larger range of uncertainty

Such diagrams (prototypes of BE-diagrams) can be useful in regional crop production planning, assessment of possible damage from climate change, and adaptation planning. Certainly, this method of aggregation and visualization of information can be easily perceived by decision-makers, including those in the field 
of adaptation planning. In our opinion, the use of gradual coloring is not expedient, because it masks the temperature thresholds which only matter for the practice.

It should be emphasized that this diagram is specific for the region (in our example, it is the Volga region) and for the plant (spring wheat). For a larger territory, as well as for a wider group of agricultural plants (for example, cereals in general), the temperature thresholds shown in Fig. 5 and their confidence limits can change significantly. It is also important to keep in mind that here the climate related event is an increase in average air temperature specifically in June in the Volga region. Therefore, it is not acceptable to replace it with a change in the global mean temperature of June, and even more so with a change in the global annual mean temperature in the scenario assessments of future risks under warming. Finally, the diagram shown in Fig. 5 describes only the consequences, not the risks. To characterize the risks, it is also necessary to take into account the probabilities of the exceedance of the respective threshold values by temperature.

We believe that the approach presented in this section can be further developed to a meta-algorithm allowing to construct BE-diagrams from a set of heterogeneous initial data in transparent and repeatable manner.

\section{Conclusions}

There is a scientific task of generalization and assessment of data presented in the scientific literature carried out by the IPCC, including data on climate change impacts on natural and socio-economic systems and on human health. It requires special methodological developments, which must be considered and approved by the IPCC as an organization and published in the form of a Guidance Note for the authors of the IPCC reports. An example is the IPCC Guidance Note for Lead Authors of the IPCC Fifth Assessment Report on Consistent Treatment of Uncertainties (Mastrandrea et al., 2010). Of course, such methodological guidance needs further development over time (Mach et al., 2017; Semenov et al., 2019). Burning ember diagrams, BE-diagrams, are widely used in the IPCC reports as a tool for synthesizing and visualizing the results of climate change impact and risk assessments. Our analysis revealed a number of shortcomings inherent to the BE-diagrams' construction. This paper provides an example of possible formalization of the procedure. For the further correct use of BEdiagrams for risk visualization in the IPCC reports, there is an urgent need to develop a comprehensive IPCC Guidance Note on the assessment and visualization of climate related risks.

\section{Acknowledgements}

The authors thank Vera N. Pavlova (All-Russian Research Institute of Agricultural Meteorology) for useful discussions. Our thanks are also due to Maria Shaskolskaya who has made helpful language comments to the manuscript. 


\section{References}

Aspinall W.P., Cooke R.M. 2013. Quantifying scientific uncertainty from expert judgement elicitation. - In: Risk and Uncertainty Assessment for Natural Hazards / eds. J. Rougier, S. Sparks, and L.J. Hill. - New York, NY: Cambridge University Press, pp. 64-99. Doi: 10.1017/CBO9781139047562.005.

Aven T., Renn O. 2015. An Evaluation of the Treatment of Risk and Uncertainties in the IPCC Reports on Climate Change. - Risk Analysis, vol. 35, No. 4, pp. 701-712. Doi: 10.1111/risa.12298.

Barayev A.I., Bakayev N.M., Vedeneyeva M.L., Volkov Ye.D., Grivanov K.P., Gromov A.G., Nesterenko A.M., Plakhotnik V.V., Sinitsyn S.S., Stepanov A.I., Suleymenov M.K., Fokeyev P.F., Shevchenko F.P., Shumakov N.S. 1978. Spring wheat. - Moscow, Kolos, 429 p. (in Russian).

Fischlin A. 2009. Do we have sufficient safety margins in climate policies? [Berücksichtigen wir in der Klimapolitik genügend Sicherheitsmargen?]. - GAIA, vol. 18, No. 3, pp. 193-199 (in German).

Gattuso J.-P., Magnan A., Billé R., Cheung W.W.L., Howes E. L., Joos F., Allemand D., Bopp L., Cooley S.R., Eakin C.M., Hoegh-Guldberg O., Kelly R.P., Pörtner H.-O., Rogers A.D., Baxter J.M., Laffoley D., Osborn D., Rankovic A., Rochette J., Sumaila U.R., Treyer S. 2015. Contrasting futures for ocean and society from different anthropogenic $\mathrm{CO}_{2}$ emissions scenarios. - Science, vol. 349, Issue 6243, aac4722. Doi: 10.1126/science.aac4722.

Haunschild R., Bornmann L., Marx W. 2016. Climate change research in view of bibliometrics. - PLoS One, vol. 11 (7), e0160393. Doi: 10.1371/journal.pone.0160393.

IPBES, 2019. Summary for policymakers of the global assessment report on biodiversity and ecosystem services of the Intergovernmental Science-Policy Platform on Biodiversity and Ecosystem Services /S. Díaz, J. Settele, E.S. Brondízio, H.T. Ngo, M. Guèze, J. Agard, A. Arneth, P. Balvanera, K.A. Brauman, S.H.M. Butchart, K.M.A. Chan, L.A. Garibaldi, K. Ichii, J. Liu, S.M. Subramanian, G.F. Midgley, P. Miloslavich, Z. Molnár, D. Obura, A. Pfaff, S. Polasky, A. Purvis, J. Razzaque, B. Reyers, R. Roy Chowdhury, Y.J. Shin, I.J. Visseren-Hamakers, K.J. Willis, and C.N. Zayas (eds.). - IPBES secretariat, Bonn, Germany, 56 p.

IPCC, 1990. Climate Change. The IPCC Impacts Assessment. Report prepared for IPCC by Working Group II /Tegart WJ. McG., G.W. Sheldon and D.C. Griffiths (eds.) - Australian Government Publishing Service, Canberra, Commonwealth of Australia.

IPCC, 2012. Managing the Risks of Extreme Events and Disasters to Advance Climate Change Adaptation. - A Special Report of Working Groups I and II of the Intergovernmental Panel on Climate Change /Field C.B., V. Barros, T.F. Stocker, D. Qin, D.J. Dokken, K.L. Ebi, M.D. Mastrandrea, K.J. Mach, G.-K. Plattner, S.K. Allen, M. Tignor, and P.M. Midgley (eds.). - Cambridge University Press, Cambridge, UK and New York, NY, USA, 582 p. 
IPCC, 2014. Summary for policymakers. - In: Climate Change 2014: Impacts, Adaptation, and Vulnerability. Part A: Global and Sectoral Aspects. Contribution of Working Group II to the Fifth Assessment Report of the Intergovernmental Panel on Climate Change /Field C.B., V.R. Barros, D.J. Dokken, K.J. Mach, M.D. Mastrandrea, T.E. Bilir, M. Chatterjee, K.L. Ebi, Y.O. Estrada, R.C. Genova, B. Girma, E.S. Kissel, A.N. Levy, S. MacCracken, P.R. Mastrandrea, and L.L. White (eds.). - Cambridge University Press, Cambridge, United Kingdom and NewYork, NY, USA, pp. 1-32.

IPCC, 2014a. Climate Change 2014: Synthesis Report. Contribution of Working Groups I, II and III to the Fifth Assessment Report of the Intergovernmental Panel on Climate Change /Core Writing Team, R.K. Pachauri and L.A. Meyer (eds.). - IPCC, Geneva, Switzerland, 151 p.

IPCC, 2018. Summary for Policymakers. - In: Global Warming of $1.5^{\circ} \mathrm{C}$. An IPCC Special Report on the impacts of global warming of $1.5^{\circ} \mathrm{C}$ above preindustrial levels and related global greenhouse gas emission pathways, in the context of strengthening the global response to the threat of climate change, sustainable development, and efforts to eradicate poverty /Masson-Delmotte V., P. Zhai, H.-O. Pörtner, D. Roberts, J. Skea, P.R. Shukla, A. Pirani, W. Moufouma-Okia, C. Péan, R. Pidcock, S. Connors, J.B.R. Matthews, Y. Chen, X. Zhou, M.I. Gomis, E. Lonnoy, T. Maycock, M. Tignor, and T. Waterfield (eds.). In press. - Available at: https://www.ipcc.ch/site/assets/uploads/sites/2/2019/05/ SR15_SPM_version_report_LR.pdf (accessed 12 May 2020).

IPCC, 2019a. IPCC Special Report on Climate Change, Desertification, Land Degradation, Sustainable Land Management, Food Security, and Greenhouse gas fluxes in Terrestrial Ecosystems. Summary for Policymakers. - Approved Draft, 41 p. - Available at: https:/www.ipcc.ch/site/assets/uploads/2019/08/Edited-SPM Approved_Microsite_FINAL.pdf (accessed 12 May 2020).

IPCC, 2019b. Summary for Policymakers. - In: IPCC Special Report on the Ocean and Cryosphere in a Changing Climate /H.-O. Pörtner, D.C. Roberts, V. Masson-Delmotte, P. Zhai, M. Tignor, E. Poloczanska, K. Mintenbeck, A. Alegría, M. Nicolai, A. Okem, J. Petzold, B. Rama, N.M. Weyer (eds.)]. - In press. Available at https:/www.ipcc.ch/site/assets/uploads/sites/3/2019/11/03_SROCC_ SPM_FINAL.pdf (accessed 12 May 2020).

Kyoto Protocol, 1997. Kyoto Protocol to the United Nations Framework Convention on Climate Change, $24 \mathrm{p}$.

De Laplace P.S. 1902. A Philosophical Essay on Probabilities. Translated from the sixth French edition. - John Wiley \& Sons, London: Chapman \& Hall, Limited, 196 p.

Lokers R., Knapen R., Janssen S., van Randen Y., Jansen J. 2016. Analysis of Big Data technologies for use in agro-environmental science. - Environmental Modelling \& Software, vol. 84, pp. 494-504. Doi: 10.1016/j.envsoft.2016.07.017.

Mach K.J., Mastrandrea M.D., Freeman P.T., Field C.B. 2017. Unleashing expert judgment in assessment. - Global Environmental Change, vol. 44, pp. 1-14. 
Mastrandrea M.D., Field C.B., Stocker T.F., Edenhofer O., Ebi K.L., Frame D.J., Held H., Kriegler E., Mach K.J., Matschoss P.R., Plattner G.-K., Yohe G.W., Zweirs F.W. 2010. Guidance Note for Lead Authors of the IPCC Fifth Assessment Report on Consistent Treatment of Uncertainties. - IPCC Cross-Working Group Meeting on Consistent Treatment of Uncertainties. Jasper Ridge, CA, USA 6-7 July 2010, Intergovernmental Panel on Climate Change (IPCC). - Available at: https://archive.ipcc.ch/pdf/supporting-material/uncertainty-guidance-note.pdf (accessed 13 May 2020).

Minx J.C., Callaghan M., Lamb W.F., Gararda J., Edenhofer O. 2017. Learning about climate change solutions in the IPCC and beyond. - Environmental Science \& Policy, vol. 77, November 2017, pp. 252-259. Doi: 10.1016/ j.envsci.2017.05.014.

Morgan M.G., Henrion M. 1990. Uncertainty: A Guide to Dealing with Uncertainty in Quantitative Risk and Policy Analysis. - Cambridge University Press, Cambridge, United Kingdom, 332 p.

von Neumann J. and Morgenstern O. 1970. Theory of Games and Economic Behavior. Translated from the third English edition. - Moscow, Nauka, 707 pp. (in Russian).

Nunez-Mir G.C., Iannone B.V. Pijanowski B.C., Kong N., Fei S. 2016. Automated content analysis: addressing the big literature challenge in ecology and evolution. - Methods in Ecology and Evolution, vol. 7 (11), pp. 1262-1272. Doi : 10.1111/2041-210x.12602.

O’Neill B.C., Oppenheimer M., Warren R., Hallegatte S., Kopp R.E., Pörtner H.-O., Scholes R., Birkmann J., Foden W., Licker R., Mach1 K.J., Marbaix Ph., Mastrandrea M.D., Price J., Takahashi K., van Ypersele J.-P., Yohe G.W. 2017. IPCC reasons for concern regarding climate change risks. - Nature Climate Change, vol. 7, pp. 28-37. Doi: 10.1038/nclimate3179.

Paris Agreement, 2015. - United Nations, 27 p. - Available at: https:// unfccc.int/files/essential_background/convention/application/pdf/english_paris_agreement.pdf (accessed $1 \overline{3}$ May 2020).

Parry M.L., Canziani O.F., Palutikof J.P., and Co-authors. 2007. Technical Summary. Climate Change 2007: Impacts, Adaptation and Vulnerability. Contribution of Working Group II to the Fourth Assessment Report of the Intergovernmental Panel on Climate Change /M.L. Parry, O.F. Canziani, J.P. Palutikof, P.J. van der Linden and C.E. Hanson, Eds. - Cambridge University Press, Cambridge, UK, pp. 23-78.

Principles Governing IPCC Work, 2013. - Intergovernmental Panel on Climate Change, Geneva, Switzerland, 2 p. - Available at https://www.ipcc.ch/site/assets/ uploads/2018/09/ipcc-principles.pdf (accessed 13 May 2020).

Rosa E.A. 1998. Metatheoretical foundations for post-normal risk. - Journal of Risk Research, vol. 1(1), pp. 15-44. 
Rosa E.A. 2003. The logical structure of the social amplification of risk framework (SARF): metatheoretical foundation and policy implications. - In: The Social Amplification of Risk /Pidgeon N., Kasperson R.E, Slovic P. (eds.). Cambridge University Press, Cambridge, United Kingdom, pp. 47-79.

Schneider S.H., Semenov S., Patwardhan A., Burton I., Magadza C.H.D., Oppenheimer M., Pittock A.B., Rahman A., Smith J.B., Suarez A., Yamin F. 2007. Assessing key vulnerabilities and the risk from climate change. Chapter 19. - In: Climate Change 2007: Impacts, Adaptation and Vulnerability. Contribution of Working Group II to the Fourth Assessment Report of the Intergovernmental Panel on Climate Change /M.L. Parry, O.F. Canziani, J.P. Palutikof, P.J. van der Linden and C.E. Hanson, Eds. - Cambridge University Press, Cambridge, UK, pp. 779-810.

Semenov S.M., Anisimov O.A., Anokhin Yu.A., Kobysheva N.V. 2008. Introduction. - In: Assessment Report on Climate Change and Its Consequences in the Russian Federation. Volume II. Consequences of Climate Change. - Moscow, Roshydromet, pp. 7-18. ISBN 978-5-904206-07-9 (in Russian).

Semenov S.M., Insarov G.E., Méndez C.L. 2019. Characterization of uncertainties in assessments of the Intergovernmental Panel on Climate Change. Fundamental and Applied Climatology, vol. 2, pp. 103-119. Doi: 10.21513/24108758-2019-2-103-119. Available at: http://downloads.igce.ru/journals/FAC/ FAC_2019/FAC_2019_2/Semenov_S_M_et_al_translation_FAC_2019_2.pdf (accessed 13 May 2020).

Smith J.B., Schellnhuber J., Mirza M.M.Q., Fankhauser S., Leemans R., Lin E., Ogallo L., Pittoc B., Richels R.G., Rosenzweig C., Tol R.S.J., Weyant J.P., Yohe G.W. 2001. Vulnerability to climate change and reasons for concern: A synthesis. Chapter 19. - In: Climate Change 2001: Impacts, adaptation, and vulnerability. Contribution of Working Group II to the Third Assessment Report of the Intergovernmental Panel on Climate Change /McCarthy J.J., Canziani O.F., Leary N.A., Dokken D.J., White K.S., eds. - Cambridge University Press, Cambridge, United Kingdom, pp. 913-967.

Smith J.B., Schneider S.H., Oppenheimer M., Yohee G.W., Haref W., Mastrandrea M.D., Patwardhan A., Burton I., Corfee-Morlot J., Magadza C.H.D., Füssel H.-M., Pittock A.B., Rahman A., Suarez A., van Ypersele J.-P. 2009. Assessing dangerous climate change through an update of the Intergovernmental Panel on Climate Change (IPCC) "reasons for concern". - PNAS, vol. 106, No. 11, pp. 4133-4137. Doi: 10.1073_pnas.0812355106.

Stockhause M., Juckes M., Chen R., Okia W.M., Pirani A., Waterfield T., Xing X., Edmunds. 2019. Data Distribution Centre Support for the IPCC Sixth Assessment. - Data Science Journal, 18:20, pp. 1-7. Doi: 10.5334/dsj-2019-020.

TG-Data, 2020. Task group on data support for climate change assessments, IPCC-LII/Doc. 8, Fifty-second session of the IPCC, Paris, France, 24-28 February 2020, 8 p. - Available at: https://www.ipcc.ch/site/assets/uploads/2019/12/ 200220200150-Doc.-8-Rev.-1-TG-Data.pdf (accessed 13 May 2020). 
The Global Risks Report. 2019. World Economic Forum. - Geneva, Switzerland, 14th Edition, 108 p. Available at: http:/www3.weforum.org/docs/ WEF_Global_Risks_Report_2019.pdf (accessed 13 May 2020).

UNFCCC, 1992. United Nations Framework Convention on Climate Change. United Nations, 25 p. - Available at: https://unfccc.int/resource/docs/convkp/ conveng.pdf (accessed 13 May 2020).

Wilkinson M.D., Dumontier M., Aalbersberg I.J., Appleton G., Axton M., Baak A., Blomberg N., Boiten J.-W., da Silva Santos L.B., Bourne P.E., Bouwman J., Brookes A.J., Clark T., Crosas M., Dillo I., Dumon O., Edmunds S., Evelo C.T., Finkers R., Gonzalez-Beltran A., Gray A.J.G., Groth P., Goble C., Grethe J.S., Heringa J., 't Hoen P.A.C., Hooft R., Kuhn T., Kok R., Kok J., Lusher S.T., Martone M.E., Mons A., Packer A.L., Persson B., Rocca-Serra P., Roos M., van Schaik R., Sansone S.-A., Schulte E., Sengstag T., Slater T., Strawn G., Swertz M.A., Thompson M., van der Lei J., van Mulligen E., Velterop J., Waagmeester A., Wittenburg P., Wolstencroft K., Zhao J., Mons B. 2016. The FAIR Guiding Principles for scientific data management and stewardship. - Scientific Data, 3: 160018. Doi: 10.1038/sdata.2016.18.

\section{Referencing this paper:}

Insarov G.E., Méndez C.L., Semenov S.M., Yanda P. Z. 2020. Concept of risk and visualization of its changes in the reports of the Intergovernmental Panel on Climate Change. - Fundamental and Applied Climatology, vol. 2, pp. 100-119. DOI:10.21513/2410-8758-2020-2-100-119.

Translation from Russian. The original is published in this volume: Fundamental and Applied Climatology, 2020, vol. 2, pp. 6-34. 